\title{
ANILLOS ANTIDEFORMANTES UTILIZADOS EN OSTEOARTRITIS
}

\author{
Claudia Patricia Escandón G. \\ T.O. UNIVERSIDAD NACIONAL \\ Unidad Especializada de Rehabilitación Integral, Duitama
}

El presente ensayo trata de manejar temas como: la Osteoartritis y sus características más evidentes, mí experiencia con los anillos utilizados en los pacientes con esta patología, menciona algunos de los materiales utilizados en la elaboración de algunos Anillos sus ventajas y desventajas, permitiendo escoger el más conveniente.

Las patologías de tipo Reumático han sido muy controvertidas dentro del área de férulas por cuanto estas se caracterizan por implicar no una sino varias articulaciones y por presentar diferentes grados degenerativos entre ellas. Por esta razón es importante hacer una muy buena valoración del segmento al cual se le va elaborar la férula, con el fin de beneficiar al paciente, bien sea a nivel de disminución de dolor, prevención o corrección de deformidades o facilitación del movimiento según el caso, y no por el contrario acarrear más problemas de los que ya presenta.

El tema llama la atención desde el punto de vista del Terapeuta Ocupacional, por cuanto la Osteoartritis afecta las artículaciones de la mano principalmente y debido a que esta se constituye en la herramienta indispensable en la ocupación de un individuo, dicha patología puede llegar a limitarlo funcionalmente, siendo nuestro deber suplir en cierta medida posibles deficiencias que se presenten en ella y en cualquier segmento de nuestro cuerpo.

En primera estancia vamos a conocer un poco acerca de la Osteoartritis:

La Osteoartritis es conocida también como Osteoatrosis o Enfermedad Articular Degenerativa. Progresa lentamente, en general tiene un curso muy benigno, sín embargo puede ocasionar mucho dolor, rigidez y gran limitación. La mayoría de las veces se presenta después de los 40 años.

Compromete en especial las articulaciones interfalángicas distales, las proximales, la trapeciometacarpiana, la cadera, la rodilla, la primera 
metatarsofalángica y las articulaciones de la columna cervical y lumbar.

El síntoma predominante de la Osteoartritis es el dolor, el cual aparece cuando se utiliza la articulación y desaparece cuando está en reposo.

Es frecuente encontrar rigidez matutina de 15 minutos, debilidad en la mañana, sensibilidad local, con dolor y crépitos cuando se realizan movimientos pasivos y aumento del tamaño de la articulación por sinovitis secundaria, por aumento del liquido sinovial o por osteofitos. En etapas tardías hay pérdida de los arcos de movimiento, gran deformidad y subluxación, los cuales resultan de la pérdida del cartílago articular, del colapso del hueso subcondral, de la formación de quistes óseos y del gran sobrecrecimiento óseo.

El diagnóstico inicialmente es clínico y se confirma con estudios radiológicos. Los exámenes de laboratorio son normales excepto si se halla asociada a una entidad metabólica o endocrina. Los hallazgos radiológicos incluyen: disminución del espacio articular, esclerosis subcondral, formación de osteofitos marginales, quistes óseos, colapsos óseos, pérdida del espacio articular con grandes deformidades articulares y subluxaciones.

El tratamiento incluye: Educación a la persona, es decir conocer las características de la enfermedad, su evolución y pronóstico, en especial que es benigna pero no curable y por tanto aspirando a lograr mejores condiciones de vida; Medios físicos como el calor, TENS, Ejercicios activos especialmente, Tratamiento Farmacológico, Tratamientos Quirúrgicos, Terapia Ocupacional y elaboración de Férulas según la necesidad.

Una vez contemplado a grandes rasgos las características más evidentes de la Osteoartritis, nos dedicaremos a las férulas; y dentro del grupo de férulas que se elaboran para individuos cuyas articulaciones de la mano se han visto afectadas por la Osteoartritis se encuentran los ANILLOS ANTIDEFORMANTES, elaborados en una gran variedad de materiales.

Los Objetivos principales de estos anillos son: prevenir y corregir deformidades en dedos, además de disminuir.dolor, proveer una buena alineación articular y permitir funcionalidad de la mano.

Estas pequeñas férulas se elaboran para deformidades como botonera, cuello de cisne, inestabilidad lateral, deformaciones en flexión, entre otros. 
Los materiales utilizados varían de duros, semiduros y suaves.

En mi experiencia he logrado observar ventajas y desventajas de los anillos que a continuación mencionaré:

\section{ANILLOS EN YESO:}

Son utilizados preferencialmente en la noche.

Ventajas: Económico, se pueden moldear sobre el paciente.

Desventajas: No son graduables (hay que elaborar uno cada vez), el material es frío, es áspero después de seco y puede lastimar la piel, debido a que no tiene un color transparente el paciente mientras duerme no puede observar si hay algún cambio, se daña con la humedad, no permite movilidad.

\section{ANILLOS EN COBRE O ACERO:}

Están indicados para uso diurno y especialmente para uso nocturno.

Ventajas: Mantienen el dedo en posición adecuada y permite cierto grado de movimiento antagonista, son graduables, estéticos de acuerdo con el acabado, económicos.

Desvantajas:Si no se acolchonan adecuadamente lastiman la piel, si el calibre del alambre no es grande la deformidad gana por deficiente resistencia del material, en ocasiones no son cómodos.

\section{ANILLOS EN MATERIALES TERMOPLASTICOS:}

De uso diurno y nocturno según indicación.

- En PVC : No los sugiero pues son muy difíciles de moldear, son pesados no se pueden moldear sobre el paciente.

- En Orthoplast:

Ventajas: Se puede moldear sobre el paciente, es cómodo, estético, pueden realizarce estáticos o dinámicos, se puede observar la articulación mientras están colocados.

Desventaja: Dificultad para conseguir el material, el costo.

Este ha sido un pequeño recuento de lo observado en mí práctica particular con relación a los Anillos Antideformantes utilizados en la Osteoartritis y los diversos materiales utilizados en ellos, espero que haya sido práctico y de utilidad para aquellas personas que puedan estar interesadas en el tema.

De igual manera, para mí sería muy enriquecedor el contar con personas expertas en el tema y con literatura que refute o confirme los aspectos observados en mi práctica particular. 
Es de anotar que aunque existen infinidad de materiales para elaborar Anillos es mínimo el acceso a estos debido al costo y baja cantidad que hay en el medio, por tal razón, se da cierta tendencia a utilizar aquellos materiales que son accequibles, de bajo costo y que terminen cumpliendo con la función deseada que en este caso debe ser: PREVENIR y/o CORREGIR DEFORMIDADES. 


\section{Bibliografía}

- ATLAS OF ORTHOTICS. American Academy of Orthopaedic Surgeons.

Second Edition. 1985. Págs. 177- 182-183.

- BYRON, P. Splinting the Arthritis Hand. Hand Ther $6: 46$ - 48. 1993.

- OVERTON EJ. ALCOTT LE : The Role of Splints in Preventing Deformity in Rheumatoid Hand and Wrist. Missouri Med: 423 - 427, 1996.

RESTREPO, Ricardo. LUGO, Luz Helena. Rehabilitaciòn en Salud. Editorial UNIVERSIDAD DE ANTIOQUIA. 1996. 